DOI 10.37882/2223-2982.2020.10.17

\title{
ВКЛАД ПРЕПОДАВАТЕЛЕЙ МИХАЙЛОВСКОЙ АРТИЛЛЕРИЙСКОЙ АКАДЕМИИ И УЧИЛИЩА В АРТИЛЛЕРИЙСКОЕ ОБРАЗОВАНИЕ ИМПЕРАТОРСКОЙ (НИКОЛАЕВСКОЙ) ВОЕННОЙ АКАДЕМИИ ГЕНЕРАЛЬНОГО ШТАБА
}

\section{CONTRIBUTION OF TEACHERS OF THE \\ MIKHAILOVSKY ARTILLERY ACADEMY \\ AND SCHOOL TO THE ARTILLERY \\ EDUCATION OF THE IMPERIAL \\ (NIKOLAEV) MILITARY ACADEMY \\ OF THE GENERAL STAFF}

\section{S. Dyakov}

Summary: The article describes the history of the creation of the higher military school in Russia in the middle of the XIX century, as well as the role and place of artillery education in the Imperial (Nikolaev) Academy of the General staff. The article analyzes the contribution of teachers of the Mikhailovsky artillery Academy and participation in the reorganization and improvement of the educational process of students of the Imperial (Nikolaev) Academy of the General staff.

Keywords: education, artillery Sciences, Imperial (Nikolaev) Academy of the General staff, Mikhailovsky artillery Academy and school, artillery shooting, artillery tactics, artillery business.
$\mathrm{B}$ России к вопросу необходимости создания высшей военной школы пришли лишь в начале 30-х годов XIX века, хотя опыт развитых стран Европы уже был. Так во Франции с 1818 года существовала высшая штабная школа, в Англии аналогичное военное заведения (Staff College) открыто в начале XIX века, в Пруссии существовавшая со времен Фридриха II Рыцарская академия в 1822 году была преобразована в Королевскую академию (Allgemeine Krigs Schulle) [1 ,2, 3, c.134].

Императорская военная академия была открыта 26 ноября (старого стиля) 1832 года и предназначалась «для образования офицеров к службе Генерального штаба» и «для вящего распространения знаний в армии» [4, c.1]. Первым директором академии в период с 1832 по 1854 годы был назначен генерал от артиллерии Иван Онуфревич Сухазанет, что в дальнейшем конечно же повлияло на место артиллерийского образования в академии. Предмет артиллерия был одним из вступительных экзаменов в академию на протяжении всего времени существования.

\author{
Дьяков Сергей Иванович \\ К.п.н., доцент, Михайловская военная \\ артиллерийская академия \\ serdyakoff@yandex.ru
}

Аннотация: В статье изложена история создания высшей военной школы в России в середине XIX века, а также роль и место артиллерийского образования в Императорской (Николаевской) академии Генерального штаба. Проанализирован вклад преподавателей Михайловской артиллерийской академии и участие в реорганизации и совершенствовании образовательного процесса у слушателей Императорской (Николаевской) академии Генерального штаба.

Ключевые слова: образование, артиллерийские науки, Императорская (Николаевская) академия Генерального штаба, Михайловская артиллерийская академия и училище, стрельба артиллерии, тактика артиллерии, артиллерийское дело.

К открытию Императорской военной академии в 1832 году в России существовала определенная система военного (начального и среднего), артиллерийского (начального и среднего), инженерного (начального и среднего) образования, которая осуществлялась системой военно-учебных заведений России под эгидой Главного управления ВУЗов. Вполне понятно, что вновь созданная Военная академия была учебным заведением нового для России типа, предназначенным для воспитания военных интеллектуалов профессиональных штабных офицеров и преподавателей для всех военно-учебных заведений страны. Диплом академии вел к вершинам не только военной карьеры, но и государственной, научной, военнодипломатической службы. Следует указать, что в 1855 году на базе Михайловского артиллерийского училища была учреждена Михайловская артиллерийская академия, что позволило поднять на новый уровень высшее артиллерийское образование в России. В этом же 1855 году было принято решение сосредоточить руководство высшим военным образованием в Генеральном штабе. В связи с этим все 3 академии: Николаевская военная академия, Николаевская инженерная академия и 
Михайловская артиллерийская академия составили как бы одну Императорскую военную академию во главе которой стоял Совет под председательством начальника Генерального штаба. На практике этот Совет не действовал, а с 1863 года вышеперечисленными академиями стали руководить соответствующие управления Военного министерства.

В Императорской (Николаевской) военной академии Генерального штаба наряду с предметами обучения слушатели изучали курс артиллерии, который относился к вспомогательным предметам обучения с названием «сведения по части артиллерии» и подразделялся на три важные дисциплинам: общие понятия об артиллерии; устройство артиллерии; применение артиллерии в полевых условиях и при осаде крепостей [5]. В академию принимали обучаемых до 1869 года 25 гвардейских и армейских офицеров, а также офицеров артиллерийского и главного инженерного училищ, а с 1879 года уже количество доходило до 100 человек, а в последующем и более. Поэтому большинство обучаемых офицеров знали артиллерию, об этом нам говорит анализ некоторых трудов [3, с.135, 6], в которых подтверждается наличие у большинства офицеров и генералов «от инфантерии» полученного ранее артиллерийского образования.

В период становления Императорской военной академии (1832-1854 гг.) курс артиллерии во многом только определялся и был довольно не точно поставлен именно для слушателей академии. Основной проблемой, которая решалась трудно, была проблема комплектования академии преподавателями, в том числе и по артиллерии. Кандидатов на преподавательские должности подбирал лично сам И.О. Сухозанет. В числе первых профессоров были назначены из артиллерийского училища полковник Н.В. Медем - тактики и истории военного искусства; майор Языков П.А. - военной географии и военной статистики; полковник Е.Х. Вессель, в последующем полковник Платов А.С. - артиллерии. На этих преподавателей легла основная нагрузка по разработке и уточнению программы курса артиллерии.

На преподавание артиллерии выделялась одна лекция, но между тем, согласно документам, курс артиллерии должен много довести до обучаемых: дать понятия не только об устройстве огнестрельного оружия, как артиллерийского, так и ручного, но и холодного; о главных основах стрельбы из орудий; об организации артиллерии нашей и иностранных армии; об использовании артиллерии в различных условиях обстановки, - в поле, при осаде и обороне крепостей. Также в начале изучения дисциплины предполагалось довести исторический обзор совершенствования огнестрельного оружия. Но эта программа не могла быть выполнена ни первым профессором Венсселем, ни его приемником, штабс-капитаном Резвым и капитаном Силичем, но постепенно сокращая ее, исключая все технические сведения и относя их приемному экзамену. В 1842 году программа стала включать всего три раздела: история артиллерии вообще и русской в особенности; организация нашей артиллерии и ее материальной части с указанием на важнейшие черты в этом отношении в иностранной артиллерии; рассмотрение действий как из артиллерийских орудий, так и ручного огнестрельного оружия. Эта сокращённая программа была изложена в учебнике капитана Силича, также в ней была представлена информация, которая нужна для поступления в академию в части касающейся артиллерии.

По мнению многих ученых того времени учебник был очень востребованным, но по мнению генерала Сухозанета в нем мало было исторических примеров, но все-таки материал, изложенный в нем был очень актуален и в последующие годы. В 1848 году Силич был заменен полковником Баумгартом, который представил свою программу изучения артиллерии: курс артиллерии должен был систематически развиваться на военноисторических основаниях: из исторического обзора артиллерии должны были истекать выводы об устройстве материальной части, организации и использования в различных условиях обстановки. Но к сожалению, это не было реализовано. Курс ограничился изложениями некоторых сражений, преимущественно Наполеоновских войн, в которых артиллерия сыграла решающую роль, а выводы по этим сражениям брались офицерами из учебника Силича. Главным достоинством в преподавании артиллерии полковником Баумгартом было окончательное исключение всей теоретической и технической части, взамен этому с 1850 года офицеры академии были допущены к осмотру разных технических артиллерийских заведений, находящихся в Санкт-Петербурге и окрестностях: порохового завода, арсенала, лаборатории и др. Ознакомление офицеров с практической стрельбой проводилось в Петергофе потом на Волковом поле [7, с.78-80].

Переводные и выпускные экзамены обучаемых имели баллы (артиллерия имела значимость 20 баллов переводных из 270 и 30 выпускных из 600 соответственно возможных, которые мог набрать обучаемый) [7, с.86].

Эволюция развития артиллерии в России, как составной части русской армии, нашла свое выражение и научных трудах. С 1830 по 1850 годы для Императорской военной академии, Михайловского артиллерийского училища, Михайловской артиллерийской академии и других ВУЗов России было создано, разработано и издано более 50 военно-теоретических трудов, пособий и изданий. К числу важных по курсу артиллерии можно назвать груды первого профессора, по артиллерии в России Е.Х. Весселя «Записки об артиллерийском искусстве» В двух частях (1830 г.) и «Начальные основания 
артиллерийского искусства» (1831 г.), которые отражали уровень артиллерийских знаний того времени. В 1851 году он издал первую часть, а в 1852 году - вторую часть своего труда «Артиллерия», где были развиты и раскрыты основные положения по применению артиллерии, в последующем (с 40-х годов), артиллеристы учатся, по курсу, составленному А.С. Платовым, а в 1909 году издан труд «Артиллерия полевых армий», автор полковник Л.Н. Гобято. Таким образом, к середине XIX века, основными центрами начала развития теории и преподавания артиллерийской науки стали: артиллерийское отделение Военно-Ученого комитета, Михайловская артиллерийская академия и Императорская академия Генерального штаба [8, с.41].

Следует сказать, что обсуждение методики обучения и преподавания курса артиллерии проводилось постоянно, о чем подтверждает факт издания в 1843 году, практически на 11-м году становления академии, «Руководства к преподаванию артиллерии в Императорской военной академии» [9]. Автор руководства - адъюнктпрофессор Императорской военной академии М. Силич одним из первых сделал попытку, оценивая состояние русской артиллерии, в основном после Отечественной войны 1812 года, показать недостаточность уровня развития артиллерийской науки, особенно «... в недостаточном приучении артиллеристов стрелять в цель, для чего в 1816 году и начались практические ученья», а отсюда обосновал необходимость повышения уровня преподавания курса артиллерии в академии.

После поражения Николаевской России в Крымской войне (1853-1856 гг.) русская военно-теоретическая мысль пыталась осмыслить пути развития военного дела. Среди причин поражения назывались и отсталая техника, устаревшие способы ведения боевых действий. Критику отсталости армии вели все военные журналы, по артиллерии в этом процессе участвовал «Артиллерийский журнал», который выступал в защиту сталепушечного производства и передовых методов подготовки артиллеристов. Особенно интересными были статьи профессоров артиллерийской академии П.Л. Лаврова «Влияние развития точных наук на успехи военного дела», И.В. Майевского «Артиллерийские лекции», А.В. Гадолина «Теория орудий, срашенных обручами», Н. Калапуцкого «Материалы для изучения стальных орудий». Все это отражалось в самом курсе по артиллерии, читаемом в Императорской военной академии преподавателями-профессорами, как в пределах тактики (тактика артиллерии), так и в курсе сведений из артиллерии. Широко практиковалось приглашать для чтения лекций, проведения занятий ученых-профессоров других академий, училищ. От Михайловской артиллерийской академии и училища приглашались выдающиеся специалисты, активные участники дальнейшего прогресса науки и техники вообще и в частности, внедрения нарезного оружия, повышения эффективности применения артиллерии, внедрения в артиллерийское производство стали, бездымных порохов, разработки теории баллистики нарезных орудий и т.д. Ими были: генерал Н.В. Майевский, ученый, совершивший переворот в области артиллерии, работы которого приобрели мировую известность; генерал А.В. Гадолин, выдающийся ученый в области артиллерийского вооружения, действительный член Петербургской академии наук, автор огромного числа работ по технологии металлов, артиллерийской технологии; другие передовые ученые того времени.

Однако для слушателей академии генерального штаба наиболее важны были занятия по боевому применению артиллерии. Так, например, для чтения лекции и проведения занятий со слушателями по курсу артиллерии приглашались профессора Михайловской артиллерийской академии, видные русские артиллеристы, такие, например, как В.Н. Шкларевич, Л.Л. Кирпичев, разработавшие совместно с генерал-майором И.Л. Чебышевым учебник «Курс артиллерии» (1863 г.).

В это время академический курс артиллерии строго ограничивался информацией, крайне необходимой для ознакомления офицеров с теми новейшими разработками военного дела в области артиллерии как у нас, так и у иностранных государств. Различные исторические исследования были вообще исключены из курса, а технические сведения ограничены очень тесными размерами и дополняются ежегодным осмотром офицерами технических артиллерийских учреждений и производством стрельбы из различного рода орудий и ручного оружия [7, с.282]. С 1869 года было положено начало сбора в академии коллекции оружия иностранных систем, что также помогало в изучении предмета и расширении военного кругозора. Этот курс артиллерии изучался в младшей кассе 1 раз в неделю, преподавал его полковник гвардейской артиллерии Эгершторм, он так умел преподносить материал, что офицеры, выходя из стен академии имели полные знания по части артиллерии необходимые в их должностях по предназначению [7, c.283].

Ввиду необходимости дальнейшего развития артиллерийского дела и наук, с учетом технических и технологических достижений в производстве орудий, боевых ракет, а также развитии теории и практики стрельбы артиллерии требовалось зачастую изменять содержание курса артиллерии с учетом новизны вопросов стратегии, оперативного искусства, тактики. Например, переход артиллерии к стрельбе с закрытых огневых позиций в начале XX века вызывал коренную ломку не только в стрельбе артиллерии, в ее боевом применении, но и в тактике действий артиллерии и полевых войск (пехоты, кавалерии), в их размещении на поле боя, в построении боевых порядков. 
К этому новшеству были причастны воспитанники Михайловской артиллерийской академии: К.Г. Гук своим замечательным трудом «Закрытая стрельба полевой артиллерии» (1882 г.), который изучался в академии Генерального штаба, а также Л.Н. Гобято, применивший впервые при обороне Порт-Артура стрельбу с закрытой огневой позиции в начале мая 1904 года.

В последующем, в 1908-1914 годах полковник Гобято Леонид Николаевич читал курс лекций по артиллерии в Николаевской академии Генерального штаба, где были изданы его важные работы «Боевые принципы и нормы полевой артиллерии» (1906 г.); «Артиллерия полевых армий» (1909, 1913-1916, части I, II) и др. В своих трудах по тактике артиллерии раскрывал и пропагандировал стрельбу с закрытых огневых позиций.

Таким образом, курс артиллерии в Императорской (Николаевской) академии Генеральною штаба со дня ее образования в 1832 году преподавался для всех слушателей и, по мере развития артиллерийского дела, науки и техники совершенствовался в области боевого применения артиллерии. Преподавание осуществлялось в рамках тактики на соответствующих кафедрах. Наибольший вклад в разработку программ и содержание курса внесли генерал-майор Медем Н.В., полковник Бессель Е.Х., полковник Платов А С. и другие. По мере развития в России артиллерии как вида оружия, в последующем как рода войск, артиллерийской науки и образования курс артиллерии в академии Генерального штаба по всем трем дисциплинам совершенствовался, а с конца XIX начала XX веков и до первой мировой войны усиленно развивался по трем основным направлениям: разработка основ преподавания общих вопросов применения русской артиллерии в сражении, бою; ознакомление с общими вопросами теории стрельбы полевой артиллерии (в том числе с закрытых огневых позиций); применении артиллерии полевых армий (корпусов).

Следует подчеркнуть, что издаваемые учебные пособия ВАГШ по вопросам боевого применения артиллерии были весьма полезны для Вооруженных Сил России, особенно для офицерского состава русской армии, в т.ч. артиллерия, ибо других изданий почти не было. Только за 2-3 года до начала первой мировой войны стали появляться такие труды, например, как: «Тактика артиллерии» преподавателя академии Генерального штаба Кельчевского, статьи и брошюры преподавателя этой же академии Б. Геруа по тактике артиллерии, аналогичные работы руководителей офицерской артиллерийской школы Л. Гобято и Н. Сапожникова, а также преподавателя этой школы Е.З. Барсукова «Записки прикладной тактики» для слушателей этой школы [10].

Вклад профессорско-преподавательского состава Михайловской артиллерийской академии в разработку трудов и самого курса артиллерии в Императорской (Николаевской) академии Генерального штаба огромен и представляет собой совокупность различных видов учебной и научной деятельности по участию в подготовке и издании уставов, наставлений, руководств и других руководящих документов для артиллерии, а также их доведение до обучаемых и популяризация знаний артиллерийских наук и боевого применения артиллерии.

Обсуждение в журналах, прежде всего, в «Артиллерийском журнале», проблемных вопросов развития материальной части артиллерии, артиллерийской науки и военного дела, проводимых на лекциях и занятиях по артиллерии, разработка программ подготовки слушателей по курсу артиллерии и учебной литературы, пособий, лекционного курса непосредственно в академии внесли огромный вклад в становление и обучение слушателей Императорской (Николаевской) академии Генерального штаба.

Такая проблема, как и что, преподавать, чему учить, всегда стояла перед преподавателями артиллерии на всем пути становления и развития академии.

Сейчас на основе анализа огромной научной литературы можно уверенно сделать вывод о том, что история развития военного артиллерийского образования в Императорской (Николаевской) академии Генерального штаба является неразрывной частью истории развития как всей артиллерии и ракет в России, так и Михайловской артиллерийской академии и училища.

\section{ЛИТЕРАТУРА}

1. Медем Н. Очерк военно-учебных заведений во Франции. СПб., 1869.

2. Медем Н. Описание военно-учебных заведений Пруссии. СПб., 1851.

3. Бескровный Л.Г. Русская армия и флот в ХІХ веке. М.: Наука, 1973.

4. Устав военной академии. СПб, 1832.

5. Лалаев М.С. Исторический очерк деятельности военного управления в России. Т. 1.СПб., 1858-1880.

6. Российские офицеры. М.: Издацентр «Анкил» - Воин., 1995.

7. Глиноецкий Н.П. Исторический очерк Николаевской академии Генерального штаба. СПб., 1882.

8. Артиллерия и ракетные войска в военной академии Генерального штаба. Исторический очерк. М., 2002. 
9. Силич М. Руководство к преподаванию артиллерии в Императорской военной академии. СПб., 1843.

10. Барсуков Е.3. Артиллерия русской армии. Воениздат, 1949.

○ Дьяков Сергей Иванович (serdyakoff@yandex.ru).

Журнал «Современная наука: актуальные проблемы теории и практики»

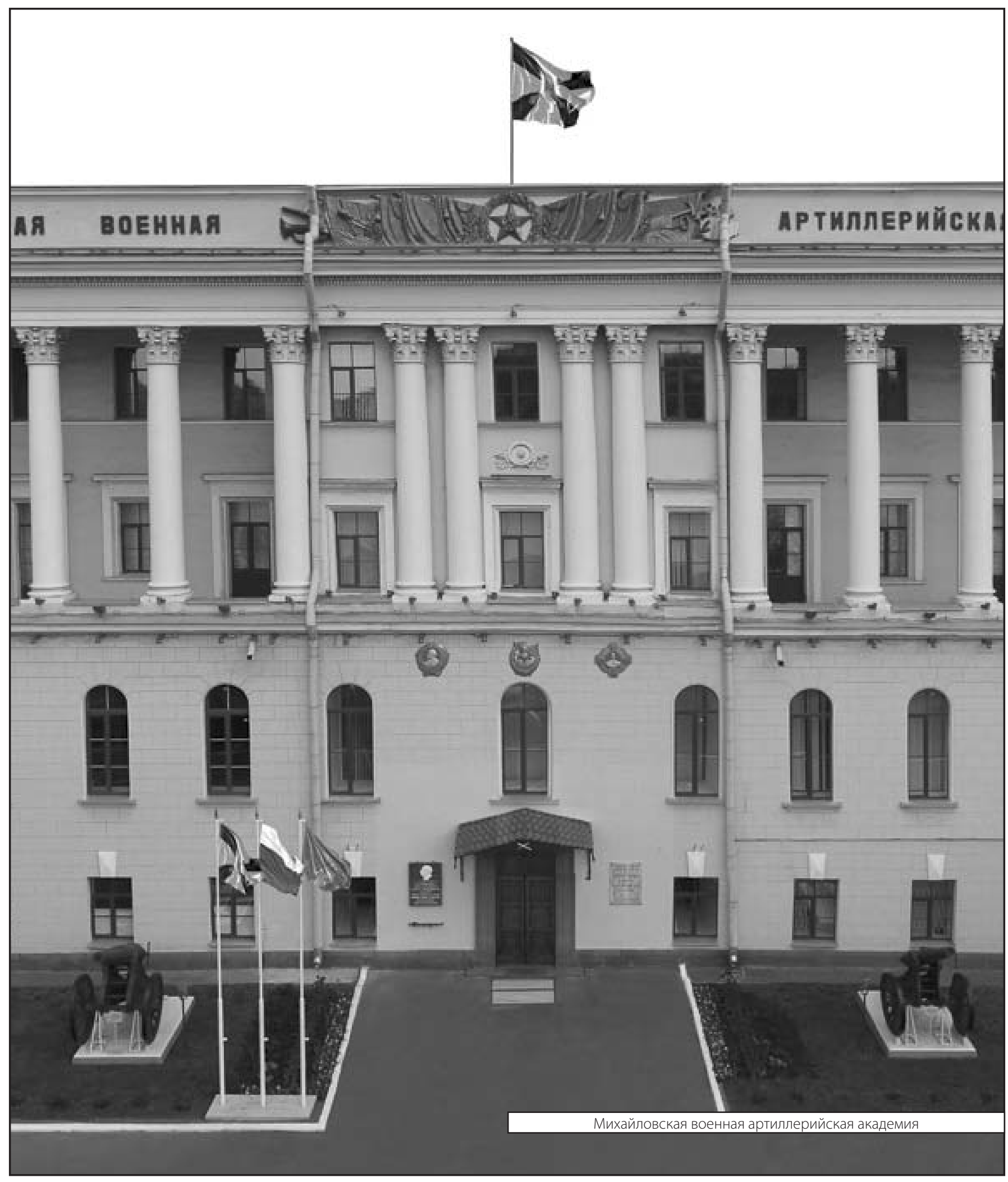

